ORIGINAL ARTICLE

\title{
MODULATION OF BONE TISSUE HISTOMORPHOMETRY AND MALONDIALDEHYDE EXPRESSION LEVELS BY VITAMIN C IN RODENTS AFTER PRENATAL NOISE EXPOSURE
}

\author{
Taya Elsa Savista ${ }^{1}$, Viskasari P. Kalanjati2 ${ }^{2 *}$, Abdurachman ${ }^{2}$ \\ ${ }^{1}$ Master Program, Basic Medical Science, Faculty of Medicine, Airlangga University, Surabaya, \\ Indonesia, \\ ${ }^{2}$ Departemen Anatomi dan Histologi, Faculty of Medicine, Airlangga University, Surabaya, \\ Indonesia.
}

*Corresponding author: viskasaripk@yahoo.com, viskasari-p-k@ fk.unair.ac.id

\begin{abstract}
Vitamin C is proposed as an antioxidant to combat the oxidative stress of prenatal noise exposure in bone tissue of newborn Wistar rats. Thirty-two Wistar mothers were administered oral vitamin C $150 \mathrm{mg} / \mathrm{kg}$ BW/day from D1 of pregnancy until delivery; white noise exposure of $95 \mathrm{~dB}, 4 \mathrm{hr} /$ day was given from D15 of pregnancy until delivery. Newborn rats were divided into 4 groups equally $(n=24)$ : K1 (distilled water), K2 (vitamin C), P1 (distilled water $+\mathrm{WN}$ ), P2 (vitamin C + $\mathrm{WN}$ ). The osteoblast and osteoclast mean cell numbers, the osteoid volume, and an oxidative stress expression level marker of malondialdehyde (MDA) were calculated from two adjacent longitudinal slices of newborn rats' tibiae using Cell Sense and Image J softwares ( $4 \mu ; 400 x$ of light microscope magnification). Data were analyze using either ANOVA and LSD post-test or Brown-Forsythe and Games Howell posttest; significance level if $\mathrm{p}<0.05$. In $\mathrm{P} 2$, the mean number of the osteoblast was significantly higher than in P1 $(\mathrm{p}<0.001)$; whilst the osteoclast mean number was significantly lower compared to other groups $(\mathrm{p}=0.03)$. In $\mathrm{P} 2$, the osteoid volume was significantly higher than in $\mathrm{P} 1(\mathrm{p}=0.021)$; with lower MDA levels than P1 $(\mathrm{p}=0.074)$. From this study, vitamin $\mathrm{C}$ could protect the newborn rat bones exposed by prenatal noise as an oxidative stressor.
\end{abstract}

Keywords: vitamin C, prenatal noise, osteogenesis, malondialdehyde

\section{INTRODUCTION}

Noise is a form of stressor that is often found in everyday life. Noise is an unwanted, unpleasant or painful sound and is one of the most widely recognized environmental stressors in the world. ${ }^{1}$ It has been reported that noise exposure in the prenatal period can trigger oxidative stress and interfere with fetal development in mice. This can interfere with fetogenic regulation of the fetus and increase the risk of bone dysfunction in adulthood. ${ }^{2}$

Exposure to noise affects the hypothalamic-pituitary-adrenal (HPA) axis and causes an increase in stress hormone levels, including glucocorticoids. Exposure to noise in mice during the prenatal period can increase glucocorticoid levels both in the maternal circulation and fetal circulation. $^{3} \quad$ Excessive glucocorticoid 
levels stimulate high free radical formation in bone tissue. These free radicals can cause lipid peroxidation, damage to cell membranes and mitochondria, and trigger DNA damage; all of which can cause an increase in osteoblast apoptosis and a decrease in bone density. ${ }^{4,5}$

Malondialdehyde (MDA) is a secondary product of lipid peroxidation due to exposure to reactive oxygen species (ROS) and other free radicals; is one of the biomarkers of cell damage due to oxidative stress ${ }^{6,7}$. This can disrupt the balance of levels of free radicals and antioxidants in the body. Vitamin $\mathrm{C}$ is a water-soluble antioxidant that has been widely reported to work as a scavenger that can prevent oxidative damage in various types of biological tissue. Vitamin $\mathrm{C}$ also plays a role in activating the differentiation of osteoblasts, increasing the bone matrix mineralization process, and can reduce osteoclast activity. ${ }^{8}$ There has not been much reported the effect of giving vitamin $\mathrm{C}$ as an antidote to the negative effects of noise on pregnancy on the growth of fetal bone tissue. In this study, the potential for anti-oxidant vitamin $\mathrm{C}$ to oxidative stressors in the form of prenatal noise exposure to the bone will be analyzed using experimental animals. It is expected that the results of the study can be useful as a basis for other studies that can eventually be applied to the wider spectrum of the community.

\section{METHODS}

This study was an experimental laboratory study with randomized posttest control group design that was approved by the Research Ethics Committee (Animal Care and Use Committee), Faculty of Veterinary Medicine, Airlangga University, Surabaya.

Twenty-four rats from 32 pregnant female Wistar rats were divided randomly into four groups with equal numbers: $\mathrm{K} 1$ (distilled water), K2 (vitamin C $150 \mathrm{mg} /$ $\mathrm{kg} /$ day), P1 (distilled water + white noise, $95 \mathrm{~dB}, 4$ hours / day), P2 (vitamin C 150 $\mathrm{mg} / \mathrm{kg} \mathrm{BB} / \mathrm{day}+$ white noise, $95 \mathrm{~dB}, 4$ hours / day). Vitamin $\mathrm{C}$ and distilled water are given orally once a day, at 09.00 a.m., starting from the first day of pregnancy to delivery. Noise is given in the form of white noise from the real-time analyzer software version 5.2.0 (Yoshimasa Electronic Inc., Japan) which is connected to the loudspeaker (Sony SRS XB30, Japan) and placed at a distance of $30 \mathrm{~cm}$ from the mouse cage. Noise exposure is given from the 15th day of pregnancy to delivery (10.00-14.00 WIB). The noise intensity is measured using a sound level meter (Krisbow, Indonesia). The K1 and $\mathrm{K} 2$ groups were the control group and were placed in different spaces without noise exposure during the study. Shortly after birth, rats' children were sacrificed by decapitation ( $n=6$ per group).

After decapitation, the mice tibia bone was taken and fixed in a $10 \%$ PBSformalin solution, followed by a decalcification process using EDTA solution for 2 weeks. The tissue is then initialized and longitudinal sliced with a thickness of $4 \mu$. The bone tissue slices were then processed into histological preparations by staining Masson's Trichrome (two preparations per animal) and observed under a light microscope (Olympus, Japan) with 400x magnification. Paraffin block slices of bone tissue were attached to IHC slides (Bio Gear, USA) and antigen retrieval and immunohistochemistry using avidin-biotin complex and citrate buffer heat-induced epitope retrieval (clone IF83, JaICa, Japan). The antibodies used in this study were anti-malondialdehyde monoclonal antibody with the dilution of 1: 250 FFB.

The process of making immunohistochemical preparations using the Bond III automated stainer (Leica Biosystem, USA) followed by exposure to DAB chromogen for 5 minutes. Negative 
Table 1. Comparative test results for the average number of osteoblast and osteoclast cells

\begin{tabular}{ccccc}
\hline \multirow{2}{*}{ Group } & \multicolumn{2}{c}{ Osteoblast } & \multicolumn{2}{c}{ Osteoclast } \\
\cline { 2 - 5 } & Mean \pm SE & ANOVA & Rerata \pm SE & Brown Forsythe \\
\hline K1 (n=6) & $45,22 \pm 1,21$ & & $2,40 \pm 0,44$ & \\
K2 (n=6) & $39,75 \pm 4,59$ & & $1,65 \pm 0,14$ & \\
P1 (n=6) & $19,62 \pm 3,24^{\text {a }}$ & $p<0.001^{*}$ & $2,06 \pm 0,34$ & $p=0.03^{*}$ \\
P2 (n=6) & $42,81 \pm 4,28$ & & $0,99 \pm 0,11^{\mathrm{b}}$ & \\
\hline
\end{tabular}

Note: The P1 group was significantly lower than the K1, K2, and P2 groups (post-test LSD). ${ }^{\mathrm{b}}$ P2 group was significantly lower than the K2 group (Games Howell post-test).

controls using slides that were not given primary antibodies, positive controls used the previous research slides in the form of tumor tissue at the Anatomy Pathology Laboratory, Faculty of Medicine, Airlangga University.

Images from a 6-10 field of view / experimental animals were taken using Cell Sense software (Olympus, Japan) and the average number of osteoblasts and osteoclasts from two bone tissue preparations per animal was calculated twice using Raster 3.0 software (Mikonos Transdata Nusantara, Indonesia). Osteoid volume and MDA expression levels of each photo of bone tissue preparations were calculated using ImageJ software (NIH, USA) after masking with the Photopea application (Czech Republic). Details of this analysis process are listed in the study of Egan et al., 2012 9. Data from 4 groups were analyzed using the ShapiroWilk normality test, Levene homogeneity test; then the one-way analysis of variance (ANOVA) test and the post-test Least Significant Difference (LSD) test were followed. Non-homogeneous data was tested with Brown-Forsythe followed by Games Howell post-test. The significance level is reached if $\mathrm{p}<0.05$.

\section{RESULTS}

The mean number of osteoblasts and osteoclasts from 4 groups can be seen in Table 1. The mean number of osteoblast cells in P2 group was significantly higher than in group P1 $(p<0.001)$, while the average number of osteoclasts was significantly lower than the other groups $(\mathrm{p}=0.03)$.

The mean osteoid volume in the P1 group was significantly lower than the other groups $(\mathrm{p}=0.021)$. The mean MDA area fraction $(\%)$ in the $\mathrm{P} 1$ group was higher than the other groups even though it was not statistically significant $(\mathrm{p}=$ 0.074). Details of data can be seen in Table 2.

\section{DISCUSSION}

In this study, noise exposure during prenatal gave a negative influence on the rat bone tissue, it was seen from the histomorphometric analysis of experimental bone tissue. The mean number of osteoblasts in the group exposed to prenatal noise decreased significantly compared to the control group. Provision of vitamin $\mathrm{C}$ proved to counteract the negative effects of prenatal noise exposure, as seen from the increase in the number of osteoblasts in the P2 group.

The results of observations of osteoid and area fractions of MDA in the mice bone tissue can be seen in Figures 1 and 2.

Noise exposure can act as oxidative stress by modulating glucocorticoid levels in both maternal and fetal circulation. ${ }^{10,11}$ 
Prenatal noise exposure causes oxidative stress in the maternal and has an impact on the decrease in expression and activity of the placental $11 \beta$-HSD2 number of osteoblasts formed decreases. ${ }^{12,14}$

Oxidative stress also triggers the apoptosis of osteoblast cells. ROS formed

Table 2. Comparative results of osteoid area average and MDA area fraction

\begin{tabular}{ccccc}
\hline \multirow{2}{*}{ Group } & \multicolumn{2}{c}{$\begin{array}{c}\text { Osteoid area }\left(\boldsymbol{\mu m}^{2}\right) \\
\mathbf{n}=\mathbf{6} \text { per group }\end{array}$} & \multicolumn{2}{c}{$\begin{array}{c}\text { MDA area fraction(\%) } \\
\mathbf{n = 3} \text { per group }\end{array}$} \\
\cline { 2 - 5 } & Rerata \pm SE & ANOVA & Rerata \pm SE & ANOVA \\
\hline K1 & $10002,28 \pm 1564,61$ & & $19,59 \pm 0,58$ & \\
K2 & $7051,63 \pm 1019,78$ & & $22,12 \pm 1,73$ & \\
P1 & $3340,20 \pm 659,59^{\text {a }}$ & $p=0.021^{*}$ & $27,25 \pm 2,12$ & \\
P2 & $7727,20 \pm 1902,68$ & & $24,39 \pm 2,18$ & \\
\hline
\end{tabular}

Note: ${ }^{\text {a }}$ Group P1 was significantly lower than group K1 and P2 (post-test LSD).

enzyme so that glucocorticoid levels from the maternal circulation can flow into the fetal circulation. Excessive glucocorticoid levels can increase the formation of reactive oxygen species (ROS), causing damage to various body tissues including bone tissue. ${ }^{12,13}$

Excessive glucocorticoid levels can increase the formation of reactive oxygen species (ROS) in bone tissue through the process of phosphorylation of $\mathrm{p} 66^{\text {shc }}$ protein in the mitochondrial internal membrane of osteoblast cells and involve Protein Kinase C $\beta$ (PKC $\beta$ ). ROS formed will increase the activity of forkhead box $\mathrm{O}$ (FOXO) which is one of the transcription factors in the cell nucleus. FOXO has a major effect on cell repair, proliferation, defense against stress, tumor suppression, and prolongation of cell life.

Excessive FOXO activity will prevent the occurrence of $\beta$-catenin bonds with $\mathrm{T}$ cells factors (TCF) in the cell nucleus, and

replace TCF to bind to $\beta$-catenin. The $\beta$ catenin and TCF bonds are important in osterix production and stimulate differentiation of mesenchymal stem cells (MSC) into osteoblasts, whereas FOXO and $\beta$-catenin bonds will suppress the Wnt signaling pathway and interfere with osteoblast differentiation so that the from the PKC $\beta$ / $p 66^{\text {shc }}$ pathway inhibits the action of the enzyme phosphatase so that the activation of cJun N-terminal kinase (JNK) continues and results in apoptosis. JNK is a kinase enzyme, part of mitogen-activated protein kinase (MAPK) which regulates several important functions such as cell growth, differentiation, cell survival ability, and cell apoptosis. JNK in osteoblasts activated due to inhibition of enzyme phosphatase by ROS causes osteoblasts to undergo apoptosis. ${ }^{12}$ Inhibition of osteoblast differentiation and apoptosis due to oxidative stress can be an early cause of bone disorders or diseases as adults. $^{2}$

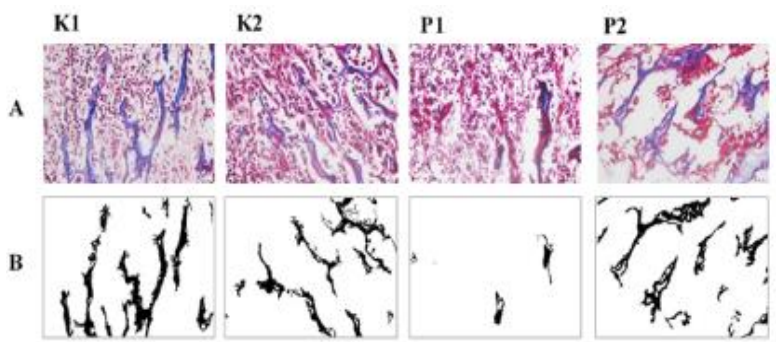

Figure 1. Observation of osteoids in mice bone tissue

Note: (A) Observation of osteoid mouse tissue in each group (Masson's Trichrome, 400x). (B) The results of osteoid masking in the rat bone tissue. The least osteoid volume appearance was detected at $\mathrm{P} 1$ compared to $\mathrm{P} 2$ and $\mathrm{K} 1$ and $\mathrm{K} 2$ controls. 


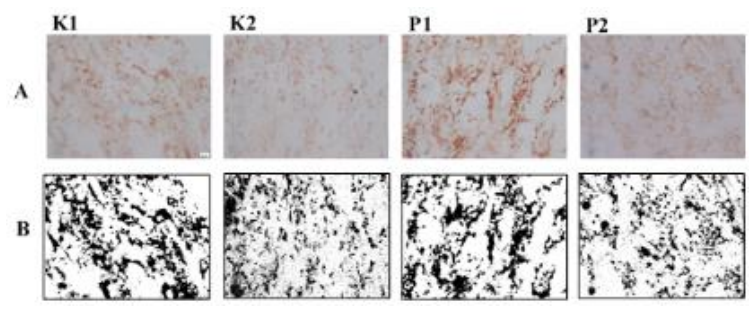

Figure 2. Results of observation of the MDA area fraction in mice bone tissue Description: (A) The results of the observation of the MDA area fraction of the mice bone tissue in each group (400x). (B) Binary image of the MDA area fraction after processing with ImageJ software. The appearance of MDA on P1 is more visible than the other groups.

Vitamin $\mathrm{C}$ acts as a scavenger that can prevent cell damage due to oxidative stress in prenatal noise exposure. Vitamin $\mathrm{C}$ or ascorbic acid has two ionized hydroxyl groups (AscH2) and under physiological conditions, ascorbic acid is found in the form of Asch - as a donor antioxidant and reacts with radicals by donating electrons to prevent the accumulation of free radicals ${ }^{15}$.

Prenatal noise exposure was also shown to modulate the osteoclastogenesis process shown in the P1 group compared to the control group, while the P2 group receiving vitamin $C$ showed a decrease in the number of osteoclasts compared to group P1.

Several previous studies showed different results regarding the effect of vitamin $\mathrm{C}$ on the process of osteoclastogenesis. Vitamin $\mathrm{C}$ can suppress osteoclastogenesis by decreasing serum lipid peroxidation and suppress the expression of receptor activator of nuclear $\kappa B$ ligand RANKL and nuclear factor (NF) $-\kappa B$ in bone marrow hematopoietic cells. RANKL and NF- $\kappa B$ are important components in differentiating osteoclast precursor cells. ${ }^{16}$

However, in vitro studies show that vitamin $\mathrm{C}$ can activate the process of osteoclastogenesis. Nihouannen et al. analyzed the effects of ascorbic acid on osteoclastogenesis using rat bone marrow culture and RAW 264.7 monocyte cells given osteoclastogenic RANKL and MCSF (macrophage colony stimulating factor). The level of oxidative stress was also observed by calculating the ratio of GSH (glutathione) and the reduced form of GSH namely GSSG (glutathione disulfide) and total GSH (GSHt). The results obtained, administration of ascorbic acid increased the number, size, and nucleation of osteoclasts and significantly decreased the ratio of GSH / GSSG and GSHt activity. ${ }^{17}$

In this study, we observed that osteoid volume in the P2 group was significantly higher than in group P1. Vitamin C can increase osteogenesis through increased synthesis of bone matrix components and/or through increased osteoblastogenesis. Bone matrix consists of organic components namely collagen protein $(90 \%)$ especially collagen type I and non-collagen proteins including osteocalcin, osteonectin, osteopontin, fibronectin, sialoprotein II, bone morphogenetic protein (BMP), and growth factors whose production can be stimulated by Vitamin C supplementation Besides this, vitamin $\mathrm{C}$ can also increase osteoblastogenesis which plays a role in osteoid secretion. ${ }^{8,18}$

Prenatal noise exposure can increase the expression of MDA bone tissue, which is a marker of oxidative stress, while vitamin $\mathrm{C}$ can prevent increased MDA expression. This is shown in group P2. ROS formed due to noise exposure in group P1 can attack lipid components of bone cell membranes composed of polyunsaturated fatty acids (PUFAs) and is called the lipid peroxidation process. Lipid peroxidation causes the breakdown of fatty acid chains into various toxic compounds including malondialdehyde (MDA) which can cause damage to cell membranes. ${ }^{19}$

Vitamin C in the P2 group can work as a scavenger oxidant by donating 
electrons to free radicals so as to produce a non-radical form. Vitamin $\mathrm{C}$ can break the redox chain of highly reactive oxidants to form new oxidants and trigger oxidative stress. This can reduce the occurrence of lipid peroxidation processes that result in cell membrane damage to cell death and prevent the formation of MDA. ${ }^{19}$

Sanbe et al. (2009) conducted a study to analyze the effect of giving vitamin $\mathrm{C}$ to the expression of RANKL and NF- $\beta$ in periodontal tissues of mice fed a high cholesterol diet. In addition to the expression of RANKL and NF- $\kappa \beta$, hexanoyl-lysine (HEL) levels as an index of lipid peroxidation were also examined. The results obtained, there was a significant increase in the expression of RANKL and NF- $\kappa \beta$ on the alveolar bone surface of rats and a significant decrease in serum HEL levels ${ }^{16}$. Giving vitamin $C$, in this case, is proven to reduce the formation of MDA which is a secondary product of lipid peroxidation.

\section{CONCLUSION}

Vitamin $\mathrm{C}$ can reduce the negative effects of oxidative stress arising from exposure to prenatal noise in the bone tissue of mice.

\section{ACKNOWLEDGMENT}

Thanks to the Head of the Anatomy and Histology Department, Faculty of Medicine, Universitas Airlangga, along with staff for the support given. Thanks to the Faculty of Medicine, Universitas Islam Sumatera Utara for the support and assistance provided.

\section{REFERENCE}

1. Wallenius MA. The interaction of noise stress and personal project stress on subjective health. $J$ Environ Psychol. 2004;24(2):167-177. doi:10.1016/j.jenvp.2003.12.002

2. Prater MR, Laudermilch CL, Liang C,
Holladay SD. Placental Oxidative Stress Alters Expression of Murine Osteogenic Genes and Impairs Fetal Skeletal Formation. Placenta. 2008;29(9):802-808. doi:10.1016/j.placenta.2008.06.010

3. Koubovec D, Geerts L, Odendaal HJ, Stein DJ, Vythilingum B. Effects of psychologic stress on fetal development and pregnancy outcome. Curr Psychiatry Rep. 2005;7(4):274280. doi:10.1007/s11920-005-0081-9

4. Gupta S, Agarwal A, Banerjee J, Alvarez JG. The Role of Oxidative Stress in Spontaneous Abortion and Recurrent Pregnancy Loss: A Systematic Review. Obstet Gynecol Surv. 2007;62(5):335-347. doi:10.1097/01.ogx.0000261644.8930 0.df

5. Zhu Z, Li X, Chen W, et al. Prenatal stress causes gender-dependent neuronal loss and oxidative stress in rat hippocampus. $J$ Neurosci Res. 2004;78(6):837-844. doi:10.1002/jnr.20338

6. Asni E, Harahap IP, Prijanti AR, et al. Pengaruh Hipoksia Berkelanjutan terhadap Kadar Malondialdehid, Glutation Tereduksi dan Aktivitas Katalase Ginjal Tikus. Maj Kedokt Indones. 2009;59:595-600.

7. Nielsen F, Mikkelsen BB, Nielsen JB, Andersen HR, Grandjean P. Plasma malondialdehyde as biomarker for oxidative stress: Reference interval and effects of life-style factors. Clin Chem. 1997;43(7):1209-1214.

8. Domazetovic V. Oxidative stress in bone remodeling: role of antioxidants. Clin Cases Miner Bone Metab. 2017;14(2):209. doi:10.11138/ccmbm/2017.14.1.209

9. Egan KP, Brennan TA, Pignolo RJ. Bone histomorphometry using free and commonly available software. Histopathology. 2012;61(6):1168$1173 . \quad$ doi:10.1111/j.1365- 
2559.2012.04333.x

10. Demirel R, Mollaoğlu H, Yeşilyurt H, et al. Noise Induces Oxidative Stress in Rat. Eur J Gen Med. 2009;6(1):2024.

11. Rakers F, Rupprecht S, Dreiling M, Witte OW. Transfer of Maternal Psychosocial Stress to the Fetus. Neurosci Biobehav Rev. 2017; (February). doi:10.1016/j.neubiorev.2017.02.019

12. Almeida M, Han L, Ambrogini E, Weinstein RS, Manolagas SC. Glucocorticoids and Tumor Necrosis Factor (Tnf) A Increase Oxidative Stress and Suppress Wnt Signaling in Osteoblasts. J Biol Chem. 2011;(15). doi:10.1074/jbc.M111.283481

13. Wauquier F, Leotoing L, Coxam V, Guicheux J, Wittrant Y. Oxidative stress in bone remodelling and disease. Trends Mol Med. 2009;15(10):468-477.

doi:10.1016/j.molmed.2009.08.004

14. Klein GL. The effect of glucocorticoids on bone and muscle. Osteoporos Sarcopenia. 2015;1(1):3945. doi:10.1016/j.afos.2015.07.008

15. Nimse SB, Pal D. Free radicals, natural antioxidants, and their reaction mechanisms. RSC Adv. 2015;5(35):27986-28006. doi:10.1039/c4ra13315c

16. Sanbe T, Tomofuji T, Ekuni D, et al. Vitamin $\mathrm{C}$ intake inhibits serum lipid peroxidation and osteoclast differentiation on alveolar bone in rats fed on a high-cholesterol diet. Arch Oral Biol. 2009;54(3):235-240. doi:10.1016/j.archoralbio.2008.11.001

17. Le Nihouannen D, Barralet JE, Fong JE, Komarova S V. Ascorbic acid accelerates osteoclast formation and death. Bone. 2010;46(5):1336-1343. doi:10.1016/j.bone.2009.11.021

18. Florencio-silva R, Rodrigues G, Sasso-cerri E, Simões MJ, Cerri PS, Cells B. Biology of Bone Tissue.
Biomed Res Int. 2015;2015:1-17.

19. Ayala A, Munoz MF, Arguelles S. Lipid Peroxidation: Production, Metabolism, and Signaling Mechanism of Malondialdehyde and 4-Hydroxy-2-Neonal. Hindawi. 2014;2014:1-31. doi:10.1155/2014/360438 